\title{
Evaluation of neonatal mortality in Buenos Aires City by place of residence and use of a health system subsector
}

\author{
Javier Meritano, M.D. ${ }^{a}$, Lorena Tsavoussian, M.D. ${ }^{a}$, Raúl Címbaro Canella, M.D. ${ }^{a}$, and \\ Claudio Solana, M.D. ${ }^{a}$
}

\begin{abstract}
Neonatal mortality is the most important component of infant mortality. Analyzing neonatal mortality is complex and does not depend exclusively on the health system.

In Buenos Aires City (CABA), between 2000 and 2012 , neonatal mortality rate was lower than the national mean rate but no changes were recorded. Besides, the difference is narrowing: in 2000, it was $46 \%$ lower but in 2012, it was $21 \%$ lower. Objective: To assess the relationship among the place of maternal residence, the use of a health system subsector, and mortality rate among newborn infants younger than 28 days old in CABA. Methods: Cross-sectional, population-based study conducted in 2011 and 2012 using data from the Office of Vital Records and the Department of Statistics and Surveys of CABA.

Results: A total of 164837 births were recorded. Theratio of births in public and private facilities has remained stable; the private subsector accounts for $57 \%$ ofbirths. Theratiobetween both subsectors was also similarin terms of gender, birth weight, and averagegestationalage. Neonatalmortality washigher among mothers who lived outside CABA $(6.55 \%$ versus $5.42 \%$, odds ratio: $1.21,95 \%$ confidence interval: 1.07-1.37, $p$ 0.0039). Among mothers living in CABA, neonatal mortality washigher in the public health subsector $(7.8 \%$ versus $4.4 \%$, odds ratio: $1.77,95 \%$ confidence interval: $1.48-2.11, p<0.001$ ). Conclusion: Unlike any other district in Argentina, CABA has a very high rate of births and deaths from other jurisdictions, especially from Greater Buenos Aires, which is not reflected in official statistics that only consider the place of parental residence.

Key words: neonatal mortality, health systems, regionalization, epidemiological factors.
\end{abstract}

Neonatology of Hospital Materno Infantil Ramón

Sardá . Autonomous City of Buenos Aires.

E-mail address:

Javier Meritano, M.D., jmeritano@gmail.com

Funding:

None.

Conflict of interest: None.

Received: 11-20-2015 Accepted: 04-21-2016 http:/ /dx.doi.org/10.5546/aap.2016.eng.405

\section{INTRODUCTION}

Neonatal mortality is the most important component of infant mortality; its analysis is complex and does not depend exclusively on the health system.

Since 1980, in Argentina, infant mortality rate (IMR) has tended to reduce, with mild fluctuations. Over the past 31 years, IMR reduced $64.8 \%$, from $33.2 \%$ in 1980 to $11.7 \%$ in 2011, and neonatal mortality rate (NMR) was $7.6 \%{ }^{1}$

NMR accounts for two-thirds of IMR and is proportionally higher when IMR is lower, as observed in developed countries or in populations with good socioeconomic and cultural conditions.

There is a global consensus regarding the fact that the reduction in infant mortality rates that occurred in the past decades in developed countries is the result of the increase in survival rate of extremely preterm infants. ${ }^{2,3}$ Neonatal networks allow for improved survival and enhanced good clinical practice. The infant's birthplace plays a major role in its survival. $^{4}$

The circumstances in which people are born, develop, live, work, and grow old, including the health system, are social determinants of health; these are the cause of the greatest health inequalities among and within countries. ${ }^{5}$ Such determinants are the subject of public policies and may be modified through effective interventions.

Over the 22-year period between 1990 and 2011, IMR tended to reduce in Buenos Aires City (CABA), which implies a $47 \%$ reduction (from $16 \%$ to $8.5 \%$ ). However, important disparities in IMR have been recorded in each municipality. ${ }^{6,7}$

In CABA, NMR has not improved as expected. In the 13-year period between 2000 and 2012, in spite of being lower than the national mean rate, no changes have been observed, and the difference is becoming smaller: while it was $46 \%$ lower in 
2000 , it was $21 \%$ lower in 2012 , based on official data (Table 1). ${ }^{1}$

Several descriptions have been made regarding this problem but no associations have been established. This would be relevant for an assessment and future intervention aimed at achieving a greater effectiveness and efficiency in health systems regarding this issue.

The goal of this study is to assess the relationship among the place of maternal residence, the use of a health system subsector, and mortality rate among newborn infants younger than 28 days old in CABA, in 2011 and 2012.

\section{MATERIALS AND METHODS}

Population-based, cross-sectional study. Birth rate data were provided by the Office of Vital Records of the City of Buenos Aires, and mortality data, by the Department of Statistics and Surveys.

\section{POPULATION \\ Inclusion criteria}

All records of infants younger than 28 days old born and deceased in CABA corresponding to either CABA or the province of Buenos Aires. The population was selected consecutively in 2011 and 2012.

\section{Exclusion criteria}

Any incomplete record or showing incompatibilities with birth weight, maternal age, gender, birth date, and facility code records.

To establish IMR in this study, all newborn infants born in CABA during the aboveindicated period (numerator) were analyzed; the denominator was built based on all newborn infants born in CABA and deceased. To this end, databases were crossed-referenced using birth weight, maternal age, gender, birth date, and facility code records.

TABLe 1. Comparison of neonatal mortality between Argentina and Buenos Aires City

\begin{tabular}{|c|c|c|c|c|c|}
\hline YEAR & Live births Argentina & Live births CABA & NMR \%o Argentina & NMR \% CABA & Difference \\
\hline 2000 & 701878 & 43587 & 10.9 & 5.9 & $46 \%$ \\
\hline 2001 & 683495 & 42171 & 10.6 & 6.2 & $42 \%$ \\
\hline 2002 & 694684 & 40825 & 11.3 & 6.3 & $44 \%$ \\
\hline 2003 & 697952 & 42136 & 10.5 & 6.4 & $39 \%$ \\
\hline 2004 & 736261 & 44019 & 9.7 & 5.7 & $41 \%$ \\
\hline 2005 & 712220 & 43064 & 8.9 & 5.2 & $42 \%$ \\
\hline 2006 & 696451 & 43582 & 8.5 & 4.9 & $42 \%$ \\
\hline 2007 & 700792 & 42183 & 8.5 & 5 & $41 \%$ \\
\hline 2008 & 746460 & 45122 & 8.3 & 4.9 & $41 \%$ \\
\hline 2009 & 745336 & 43584 & 8 & 5.8 & $28 \%$ \\
\hline 2010 & 756176 & 44347 & 7.9 & 4.5 & $43 \%$ \\
\hline 2011 & 758042 & 45280 & 7.6 & 5.5 & $29 \%$ \\
\hline 2012 & 738318 & 43733 & 7.5 & 5.9 & $21 \%$ \\
\hline \multicolumn{3}{|c|}{ Reduction in NMR 2000-2012 } & $31 \%$ & $0 \%$ & \\
\hline
\end{tabular}

Source: Department of Health Statistics and Information. Ministry of Health of Argentina.

CABA: Buenos Aires City; NMR: neonatal mortality rate.

TABLE 2. Study outcome measures by category

\section{Output variable}

1. Death (dichotomous)

Predictive outcome measures

1. Place of maternal residence (in CABA versus outside CABA, dichotomous)

2. Use of a health system subsector (public health care provider versus SSP health care provider, dichotomous)

Control outcome measures

1. Sex (male, female)

2. Gestational age (in weeks)

3. Age at time of death (dichotomous, early NMR up to 6 days old, late NMR from 7 to 27 days old, overall NMR younger than 28 days old)

4. Birth weight (in grams)

5. Maternal age (in years) 


\section{Outcome measures}

Outcome measures are described in Table 2 by category.

\section{Ethical considerations}

The study is associated with a grant awarded by the Government of CABA and has been approved by the corresponding Research Ethics Committee.

\section{Analysis}

Results are presented in two different sections: birth rate analysis and mortality rate analysis; in addition, mortality data in the sub-population with a birth weight between $500 \mathrm{~g}$ and $1499 \mathrm{~g}$ are also presented.

The incidence of outcome measures was described as mean and percentages with their corresponding $95 \%$ confidence interval (CI) or standard deviation, as applicable. The association among dichotomous outcome measures was assessed using the $\chi^{2}$ test, and odds ratios (ORs) with their corresponding 95\% CIs were estimated.
For a total of approximately 80000 newborn infants born per year in the studied territory, the population was enough to identify a difference of at least $0.04 \%$ in predictive outcome measures for the output variable, with a $95 \%$ confidence level and an $80 \%$ power.

Analysis was performed using the EpiInfo ${ }^{\mathrm{TM}}$ statistical software, version 3.5.1 for Windows. A value of $p<0.05$ was considered significant.

\section{RESULTS}

\section{Statistical analysis: Birth rate}

A total of 164691 newborn infants were born between 2011 and 2012. The number of births remained stable in both years. The ratio of births in public and social security/private (SSP) facilities also remained stable; the latter subsector accounts for most births.

Most births from mothers living in CABA take place in the SSP subsector $(64.7 \%)$ (Table 3).

The ratio of gender, birth weight, gestational age, and maternal age was similar between both subsectors and between those living in and

TABLE 3. CSociodemographic characteristics of infants born in Buenos Aires City by place of residence. Years 2011 and 2012

\begin{tabular}{|c|c|c|c|}
\hline & & CABA & Outside CABA \\
\hline \multicolumn{2}{|r|}{ Total, n (\%) } & $89099(54.1)$ & $75592(45.9)$ \\
\hline & Public sector, $n(\%)$ & $32374(34.8)$ & $34207(45.2)$ \\
\hline & Male sex, n (\%)16434 (50.8) & $16434(50.8)$ & $17462(51)$ \\
\hline & Mean birth weight in grams (SD) & $3359(580)$ & $3290(662)$ \\
\hline & Mean gestational age in weeks (SD) & $38.97(1.92)$ & $40.12(1.96)$ \\
\hline & Mean maternal age in years (SD) & $26.2(6.46)$ & $25.85(6.54)$ \\
\hline \multirow[t]{5}{*}{ b) } & Social security/private sector, n (\%) & $56725(64.7)$ & $41385(54.6)$ \\
\hline & Male sex, n (\%)29083 (51.3) & $29083(51.3)$ & $21098(51)$ \\
\hline & Mean birth weight in grams (SD) & $3254(554)$ & $3225(626)$ \\
\hline & Mean gestational age in weeks (SD) & $38.51(1.9)$ & $38.95(1.9)$ \\
\hline & Mean maternal age in years (SD) & $31.79(5.59)$ & $30.72(6.01)$ \\
\hline
\end{tabular}

CABA: Buenos Aires City, SD: standard deviation.

TABLE 4. Maternal population grouped by age range, place of residence, and use of a health system subsector. Years 2011 and 2012 (No data 2498)

\begin{tabular}{|c|c|c|}
\hline \multirow{2}{*}{$\begin{array}{l}\text { Place of residence } \\
\text { Age range in years }\end{array}$} & \multicolumn{2}{|c|}{ CABA } \\
\hline & Public & Social security/private \\
\hline $10-17, \mathrm{n}(\%)$ & $1773(5.8)$ & $486(0.8)$ \\
\hline $18-45, \mathrm{n}(\%)$ & $28468(94)$ & $55611(98.7)$ \\
\hline $46-60, \mathrm{n}(\%)$ & $17(0.05)$ & $199(0.3)$ \\
\hline Residencia & & Outside CABA \\
\hline Age range in years & Public & Social security/private \\
\hline $10-17, \mathrm{n}(\%)$ & $2347(6.9)$ & $736(1.8)$ \\
\hline $18-45, \mathrm{n}(\%)$ & 31797 (93) & $40522(98)$ \\
\hline $46-60, \mathrm{n}(\%)$ & $26(0.07)$ & $108(0.2)$ \\
\hline
\end{tabular}

CABA: Buenos Aires City. 
outside CABA (Table 3).

A distinctive feature of the public subsector is adolescent pregnancy, which is higher among those living outside CABA. When compared by age groups, a statistically significant difference was observed in the chance that adolescent mothers from CABA have of delivering their children in public hospitals (OR 7.15, 95\% CI: 6.46-7.91, $p<0.001)$. The result is similar in the population from outside CABA, but the association was weaker (OR 4.07, 95\% CI: 3.74$4.43, p<0.001$ ).

In contrast, the ratio of mothers older than 17 years old and older than 45 years old is significantly higher in the SSP health subsector of CABA; similar results were observed in the population from outside CABA, and a weaker association (Table 4).

No differences were observed in terms of gestational age; the number of extremely preterm newborn infants is similar across all populations.

No differences were observed either among populations in terms of birth weight. The number of preterm newborn infants with a birth weight of less than 1500 grams was similar across all subgroups (Table 3).

\section{Mortality analysis}

To reduce the bias of deceased infants not living in CABA, birth and death databases were cross-referenced. Out of the 693 infants deceased between 2011 and 2012, it was confirmed that 491 $(71 \%)$ had been born and died in CABA but their mother did not live in the city.

CABA has the lowest IMR in Argentina, and NMR is the greatest component of IMR. Among
CABA residents, mortality is twice as high in the public subsector than in the SSP subsector $(7.8 \%$ o versus $4.4 \%$ ).

NMR among residents from outside CABA is significantly higher than among CABA residents (6.55\% versus $5.42 \%$, OR $1.21,95 \%$ CI: 1.07 $1.37, p 0.003)$; in turn, mortality is higher among residents from outside $\mathrm{CABA}$ in the public subsector (Table 5).

Among CABA residents, the different NMR categories are higher and statistically significant in the public subsector compared to the SSP subsector. For early NMR, OR was 1.72, 95\% CI was 1.4-2.12, and $p<0.001$. For late NMR, OR was $1.92,95 \%$ CI was $1.34-2.73$, and $p<0.001$. For overall NMR, OR was 1.77, 95\% CI was 1.48-2.11, and $p<0.001$.

The same differences were observed among residents from outside CABA but the strength of the association for early NMR was different: OR $1.25,95 \%$ CI: 1.04-1.49, $p<0.05$. In this case, in terms of late NMR, no significant differences were observed: OR 0.87, 95\% CI: 0.64-1.2, $p 0.86$. For overall NMR, OR was $1.16,95 \%$ CI was 0.97 1.39 , and $p 0.09$.

The analysis of neonatal mortality in the population with a birth weight between 500 grams and 1499 grams among residents from outside CABA shows that it is significantly higher (OR 2.09, 95\% CI: 1.61-2.71, $p<0.001$ ). Among CABA residents, mortality is higher in the public subsector than in the SSP subsector (OR 1.61, 95\% CI: 1.06-2.47, $p<0.03$ ). The same difference was observed among residents from outside CABA (OR 1.39, 95\% CI: 1.01-1.93, p 0.0441) (Table 6).

TABLE 5. Neonatal mortality and mortality rates grouped by category, place of residence, and subsector of the health system. Years 2011 and 2012

\begin{tabular}{|c|c|c|c|c|}
\hline Place of residence & CABA & Outside CABA & OR $(95 \%$ CI $)$ & $p$ \\
\hline Early neonatal mortality rate, \%o (n) & $4(357)$ & $4.38(332)$ & $1.09(0.94-1.27)$ & 0.23 \\
\hline Late neonatal mortality rate, \%o (n) & $1.42(126)$ & $2.17(164)$ & $1.53(1.21-1.93)$ & $<0.001$ \\
\hline Neonatal mortality rate, \%о (n) & $5.42(483)$ & $6.55(496)$ & $1.21(1.07-1.37)$ & 0.003 \\
\hline \multicolumn{5}{|l|}{ Place of residence in CABA } \\
\hline Subsector of the health system & Public & SSP & OR $(95 \% \mathrm{CI})$ & $p$ \\
\hline Early neonatal mortality rate, \%о (n) & $5.6(171)$ & $3.3(186)$ & $1.72(1.4-2.12)$ & $<0.001$ \\
\hline Late neonatal mortality rate, \%o (n) & $2.1(64)$ & $1.1(62)$ & $1.92(1.34-2.73)$ & $<0.001$ \\
\hline Neonatal mortality rate, \%о (n) & $7.8(235)$ & $4.4(248)$ & $1.77(1.48-2.11)$ & $<0.001$ \\
\hline \multicolumn{5}{|l|}{ Place of residence outside CABA } \\
\hline Subsector of the health system & Public & SSP & OR $(95 \% \mathrm{CI})$ & $p$ \\
\hline Early neonatal mortality rate, \%о (n) & $5.09(174)$ & $3.81(158)$ & $1.33(1.08-1.66)$ & 0.0086 \\
\hline Late neonatal mortality rate, \%o (n) & $2.03(69)$ & $2.3(95)$ & $0.87(0.64-1.2)$ & 0.4175 \\
\hline Neonatal mortality rate, \%о (n) & $7.1(243)$ & $6.11(253)$ & $1.16(0.97-1.39)$ & 0.09 \\
\hline
\end{tabular}

CABA: Buenos Aires City, OR: odds ratio, CI: confidence interval, SSP: social security/private subsector. 


\section{DISCUSSION}

The first conclusion of this study is that, unlike any other district in Argentina, CABA has a very high rate of births and deaths from other jurisdictions, especially from Greater Buenos Aires, which is not reflected in official statistics that only consider the place of parental residence. This is a reflection of the urgent need to validate and articulate measures to integrate CABA and the nearest areas of Greater Buenos Aires into a single health region, both in terms of health care and statistical analysis. Otherwise, it would be like looking into half of the reality in relation to statistics and neonatal outcomes, for example.

The main strength of this study lies in record reliability. A potential weakness of this study is that the number of deceased infants born in CABA and whose parents lived outside CABA was established by cross-referencing birth and death record databases (using birth weight, maternal age, gender, birth date, and facility code records).

When numbers are compared, striking differences are observed by place of residence. While CABA residents have one of the lowest NMRs in Argentina (5.57\%o), the rate is higher than the national mean rate among those who live outside CABA and use the same health system $\left(10.3 \%\right.$ versus $7.59 \%$ o) ${ }^{8}$

To address this problem, it is critical to recognize that the Argentine health system is characterized by segmentation and fragmentation (in terms of regulation and territory). This results in major hurdles for compliance with health rights. ${ }^{9}$

Another major aspect of health coverage is that it is distributed according to the population's income level. A national study indicated that dependence on public health services is greater as the family per capita income is lower. ${ }^{9}$
When analyzed by territory, the number of infant deaths is $10 \%$ higher in the province of Buenos Aires when comparing municipalities in a good situation and those in a bad situation, while such risk is $150 \%$ higher among the different municipalities of CABA. ${ }^{10}$

The health system established here is copied from the curative model, which, on the one side, shows a disproportionate increase in neonatal equipment and advanced techniques and, on the other side, provides services with a high prevalence of infections, few trained nurse staff, and health care providers who are seldom found in health facilities, lack practice guidelines or standards, and fail to complete their training on one technique before learning another. ${ }^{11}$

The number of antenatal care visits may provide information on pregnancy care, early access to the system, and the possibilities of implementing preventive or care measures. In $2011,51.1 \%$ of pregnant women from Greater Buenos Aires and $57.8 \%$ of pregnant women from CABA had received adequate antenatal care, ${ }^{12}$ and many of them did not meet acceptable requirements in terms of early initiation, distribution, comprehensiveness, and quality. Only $30 \%$ of antenatal care is started in an early manner during the first quarter.

Articulation between health promotion activities developed at a community level and primary health care services, and that between these services and maternity centers where mother and child care is provided is still insufficient. Poverty makes the situation worse because it intensifies the negative impact that the lack of care has on women regarding the preservation of their reproductive health and the adequate prognosis of their pregnancy and their newborn infants. ${ }^{13}$

TABLE 6. Neonatal mortality in the population born with 500-1499 grams by place of residence and subsector of the health system. Years 2011 and 2012

\begin{tabular}{ccccc}
\hline Place of residence & CABA & Outside CABA & OR (95\% CI) & $p$ \\
\hline Neonatal mortality, \% (n) & $10.23(103)$ & $19.28(182)$ & $2.09(1.61-2.71)$ & $<0.001$ \\
\hline $\begin{array}{c}\text { CABA } \\
\text { Subsector of the health system }\end{array}$ & Public & SSP & OR (95\% CI) & $p$ \\
\hline $\begin{array}{c}\text { Neonatal mortality, \% (n) } \\
\text { Outside CABA }\end{array}$ & $20(47)$ & $12(56)$ & $1.61(1.06-2.47)$ & $<0.03$ \\
$\begin{array}{c}\text { Subsector of the health system } \\
\text { Neonatal mortality, \% (n) }\end{array}$ & Public & SSP & OR (95\% CI) & $p$ \\
\hline
\end{tabular}

CABA: Buenos Aires City, OR: odds ratio, CI: confidence interval, SSP: social security/private subsector. 
Approximately 70000 adolescents from developing countries die every year due to pregnancy- and childbirth-related conditions. Pregnant adolescents tend to come from low income households and have poor nutrition. ${ }^{14-16}$ In our study, the estimated percentage of girls younger than 18 years old giving birth in the public subsector was five times higher than in the SSP subsector.

Poor and illiterate or poorly-educated girls are more likely to become pregnant than rich, educated girls from urban regions. ${ }^{14}$ Birth death rate, morbidity and infant deaths are $50 \%$ higher among newborn infants born from adolescents than among those born from 20-29-year-old girls. ${ }^{17-19}$

In the analysis of the population with a birth weight between 500 grams and 1499 grams, the discussion focuses on the ratio of nurses and the level of care. It has been demonstrated that survival is associated with the number of specialized nurses. ${ }^{20}$ Having more than 1.2 nurses/ patient reduces the probability of mortality by $42 \% .{ }^{20}$ Callaghan showed that the chance of death decreased by $82 \%$ when the nurse/patient ratio was 1.7 or higher. ${ }^{3}$ Studies conducted in other settings also described such differences. ${ }^{21}$

An inadequate regionalization of perinatal care in the metropolitan area is also a major aspect of this analysis. Regional programs were designed to organize services so that women and children at high risk would receive care at hospitals with the experience and technology necessary to ensure their optimal care. Maternity centers were classified into three levels of care, transport systems were established, and links were developed to maintain training at the lower care settings that referred patients to tertiary care settings. Experiences from different countries have been published, which assessed results from regionalized perinatal systems regarding a single indicator: neonatal mortality, especially among newborn infants with a birth weight of less than 1500 grams. In different settings and health systems, regionalization appears to have a positive effect on mother and child indicators. Experiences from Canada, Portugal, Chile, and the United Kingdom support this policy as a manner of health care organization. ${ }^{22}$

Finally, the following is prevalent in public hospitals: adolescent pregnancy, a lower level of education, lack of antenatal care, lower corticosteroid use, presence of gestational diabetes (in relation to malnutrition), and chorioamnionitis. Such higher risk may be related to poverty, poor nutrition, smoking, alcohol use, and poor health conditions prior to pregnancy..$^{23}$

It is necessary to further broaden research on neonatal mortality, place of residence, living conditions, access to the health system and health care providers, which have a direct impact on newborn infants' survival possibilities.

As a result of this discussion, it is possible to appreciate the value that our society gives to health and realize that its centrality is vital for the full achievement of individual opportunities. Health and health equity should become collective goals that involve every government and civil society sector, not just the health sector, and specifically, they should not be exclusively restricted to the health system.

Therefore, the challenge remains to know the characteristics of our health inequalities and their determinants, which play different roles in the different sectors of our population.

\section{CONCLUSION}

Unlike any other district in Argentina, CABA has a very high rate of births and deaths from other jurisdictions, especially from Greater Buenos Aires, which is not reflected in official statistics that only consider the place of parental residence.

Future studies should focus on broadening knowledge on associated social determinants.

\section{REFERENCES}

1. Argentina. Ministerio de Salud de la Nación. Dirección de Estadística e Información en Salud. Estadísticas vitales. Información básica año 2011. Buenos Aires: Ministerio de Salud dela Nación; 2012. [Accessed on:September 1 $1^{\text {st }}, 2014$. Availableat:http:/ / www.bvs.org.ar/pdf/anuario11.pdf.

2. Ramos Ramos A, Martínez Ramírez A, Morales Fernández A, Valdez López RM. La prematurez y sus repercusiones en el crecimiento y desarrollo del niño, en la zona metropolitana de Guadalajara, Jalisco, México. Cad Saude Publica 1998;14(2):313-8.

3. Callaghan LA, Cartwright DW, O'Rourke P, Davies MW. Infant to staff ratios and risk of mortality in very low birthweight infants. Arch Dis Child Fetal Neonatal Ed 2003;88(2):F94-7.

4. Hübner ME, Nazer J, Juárez de León G. Estrategias para mejorar la sobrevida del prematuro extremo. Rev Chil Pediatr 2009;80(6):551-9.

5. Organización Mundial de la Salud. Determinantes sociales de la salud. Subsanar las desigualdades en una generación: alcanzar la equidad sanitaria actuando sobrelos determinantes sociales de la salud. Informe. Ginebra:OMS; 2009. [Accessed on:September 15 ,2014. Available at: http:/ / www.who.int/social_determinants/thecommission/ finalreport/es/.

6. Vettore MV, Gama SG, Lamarca Gde A, Schilithz AO, et al. Housing conditions as a social determinant of low birthweight and preterm low birthweight. Rev Saude Publica 2010;44(6):1021-31. 
7. Gobierno de la Ciudad de Buenos Aires. Dirección General deEstadísticas y Censos. La mortalidad infantilen la Ciudad de Buenos Aires 2000-2011. Buenos Aires: GCBA; 2012. [Accessed on: September 1st, 2014. Available at: http:// www.estadisticaciudad.gob.ar/eyc/?p=38773.

8. Sociedad Argentina dePediatría, UNICEF Argentina. Salud materno-infanto-juvenil en cifras 2013. Buenos Aires: SAP; 2013. [Accessed on: April 21 ${ }^{\text {st }}$, 2016. Available at: http:// www.unicef.org/argentina/spanish/salud_SapUnicef_ cifras2013.pdf.

9. Organización Panamericana de la Salud. Programa Naciones Unidas para el Desarrollo. El sistema de salud argentino y su trayectoria de largo plazo: logros alcanzados y desafíos futuros. Buenos Aires: PNUD; 2011. [Accessed on: April 21 ${ }^{\text {st }}$, 2016. Available at: http://www.undp. org/content/argentina/es/home/library/human_ development/aportes-para-el-desarrollo-humano-enargentina-2011--el-sistema-.html.

10. Comes Y, Fures NO. Estudio comparativo de las desigualdades sociales en la mortalidad infantil en el área metropolitana de Buenos Aires Año 2011. Epidemiología y Salud 2012;1(1):6-10.

11. De Sarasqueta P. ¿Cuál es el modelo? Rev Hosp Matern Infant Ramon Sardá 2001;20(2):50-1.

12. Argentina. Ministerio deSalud dela Nación. Primerinforme nacional de relevamiento epidemiológico SIP-Gestión. Buenos Aires: Organización Panamericana de la Salud; 2013. [Accessed on:September $1^{\text {st }}$, 2015. Availableat: http:// publicaciones.ops.org.ar/publicaciones/publicaciones $\% 20$ virtuales/SIP-G_Anexos/pdfPublicacion/SIP-G.pdf.

13. Argentina. Ministerio de Salud de la Nación. Guía de Seguimiento del Recién Nacido de Riesgo: Unidad Coordinadora de Programas Materno Infantiles Comisión y Nutricionales. Buenos Aires: Ministerio de Salud de laNación; 2001.

14. Fondo de Población de las Naciones Unidas. Maternidad en la niñez: enfrentar el reto del embarazo en adolescentes.
New York: UNFPA; 2013. [Accessed on: April 21 ${ }^{\text {st }}, 2016$. Available at: http:/ / www.unfpa.org.mx/publicaciones / SP-SWOP2013.pdf.

15. Gogna M. Embarazo y maternidad en la adolescencia. Estereotipos, evidencias y propuestas para políticas públicas. Buenos Aires: CEDES-UNICEF; 2005.

16. World Health Organization. Global and regional estimates of violence against women: prevalence and health effects of intimate partner violence and non-partner sexual violence. Geneva: WHO; 2013.

17. Olausson PO, Cnattingius S, Haglund B. Teenage pregnancies and risk of late fetal death and infant mortality. Br J Obstet Gynaecol 1999;106(2):116-21.

18. Draper ES, Manktelow B, Field DJ, James D. Prediction of survival for preterm births by weight and gestational age: retrospective population based study. BMJ 1999;319(7217):1093-7.

19. Bolzán A, Norry M, Borguetti M, Velez M, et al. La embarazada adolescente como grupo de riesgo obstétrico de dos distritos de la provincia de Buenos Aires, 1996-1997. Obstet Ginecol Latinoam 1998;56(2):80-6.

20. Hamilton KE, Redshaw ME, Tarnow-Mordi W. Nurse staffing in relation to risk-adjusted mortality in neonatal care. Arch Dis Child Fetal Neonatal Ed 2007;92(2):99-103.

21. Grandi C, González A, Meritano J, Grupo Colaborativo Neocosur. Riesgo de morbineonatal mortality de recién nacidos menores de 1500 gramos asociado al volumen de pacientes, personal médico y de enfermería: una investigación multicéntrica latinoamericana. Arch Argent Pediatr 2010;108(6):499-510.

22. Argentina.MinisteriodeSalud dela Nación. Regionalización de la atención perinatal. Mayo 2010. Buenos Aires: Ministerio de Salud de la Nación; 2011.

23. Alazraqui M,Spinelli H. Desigualdades en salud en el nivel local-municipal. Buenos Aires: Universidad Nacional de Lanús; 2008:153-62. 